\title{
GODS LEWENDE WOORD EN DIE MENS
}

\section{Gods lewende Woord.}

In sy proefskrif: „Klaarheid en interpretasie" praat $\mathrm{dr}$. H. W. Rossouw, net soos vele in ons tyd wat allerlei reserwes daarop nahou t.o.v. die letterlike inspirasie van die Skrif, dikwels van "Gods lewende Woord". Hy het dit veral teen die Ortodoksie wat na die Reformasietyd 'n teologie probeer uitbou het, waarby hulle formeel die Aristotelies-skolastiese metodiek van metafisika en logika gebruik het om 'n leersisteem van stabiele waarhede en sillogistiese konklusies op te stel wat dan in die plek van die "lewende Woord" gefunksioneer het.

Hierteen trek Rossouw dan sterk te velde. Ons moet weer terugkeer na die dinamies-funksionele denke van die Hervormers. Ons moet teologie beoefen coram Deo - voor Gods aangesig. Ons moet nie as anonieme toeskouers reflekteer oor die "waarhede" van Gods Woord nie, maar in die konkrete toegesprokenheid deur die lewende Woord van God.') Volgens Rossouw het die Ortodoksie daarmee nie meer die kerklike verkondiging gedien nie en ook die onafgeslotenheid en eskatologiese openheid van die teologie prysgegee. ${ }^{2}$ ) Die "lewende Woord" wat niks anders is nie as Christus self wat deur die werking van sy Gees in die verkondiging van die Skrif teenwoordig is, sê Rossouw, is daarmee ingeruil vir 'n metafisiese leersisteem van kerklike doktrine. ${ }^{3}$ ) Hiermee kom Rossouw en die rigting wat hy verteenwoordig gevaarlik naby die vaarwaters van die Barthianisme. Dis vandag 'n bekende tendens, ook by die Gereformeerde denkers, om die absolute ge',ag van die Skrif te devalueer, deur die Skrif as 't ware uit te speel teen Christus wat "die lewende Woord" is.

As Rossouw bv. sê dat die kopula in: Die Skrif is Gods Woord, gesien moet word as 'n ,bclofte wat vanuit die heilsgebeurlike verifikasie daarvan deur die selfinterpretasie van die Gees as 'n belydenis van geloof uitgespreek word",4) dan wonder mens of Barth so 'n stelling nie sal onderskryf nie? Waarskynlik voel hy self dat sy stelling al te "dialekties" klink en wil hy dan in 'n voetnoot verduidelik dat daar wel onderskeid is tussen die kopula: "is" en "die Bybel word Gods Woord" by Barth. 
Maar as die ,is" dan so oopstaan en eintlik net 'n belofte inhou wat deur die Gees daarin gelê word, dan is die Bybel tog maar net Gods Woord vir sover dit Gods Woord vir ons word.

As Rossouw nou verder redeneer dat die ,goddelike" karakter van die Skrif deur Ortodoksie op so ' $n$ wyse geformaliseer word dat dit, afgesien van die inhoud van die Skrif, as 'n soort bonatuurlike Boek gesien word waarby elke woord en selfs die vokaaltekens as geïnspireerd beskou word, en die funksie van die Bybelskrywers tot 'n minimum gereduseer word om dit des te meer as Goddelike leer- en wetboek te handhaaf, ${ }^{5}$ ) dan vind ons die hele redenasie bedenklik.

Al sê Rossouw dit nie met soveel woorde nie, kan hieruit afgelei word dat die Bybel wesenlik op één lyn lê met ander menslike boeke. Dit is nie in homself 'n ander soort Boek wat bo-natuurlik geïnspireer is nie, maar hy bevat alleen die kerugma of heilsboodskap en is dan in soverre wel Gods Woord. O.i. word hier 'n gevaarlike teëstelling tussen vorm en inhoud gemaak. Dit blyk ook daaruit dat Rossouw meen dat hierdie onfeilbaarheids-teorie van die Ortodoksie insluit dat die Skrif ook in natuurwetenskaplike sin Goddelike waarheid bevat ook t.o.v. historiese e.a. aspekte.

Dit beteken, sê hy, dat die ,lewende Woord" op 'n teoretiese vlak gedisponeer word en die Skrif dan 'n weergawe bevat van 'n objektiewe stand van sake wat feilloos korrek en juis is. Verder behels dit dat ,elke onderdeel van die Skrif dieselfde aanspraak op 'n absolute geldigheid" het. En dan maak hy die kritiese opmerking dat ,juis in hierdie leer van die wetenskaplike feilloosheid van die Skrif blyk... hoedat die gesag van die Skrif getransponeer word op 'n vlak wat vreemd is aan die sola scriptura van die Reformasie".6)

Blykbaar wil Rossouw die inspirasie dan net beperk tot die dinge wat verband hou met die kerugmatiese inhoud van die Skrif, terwyl dit in ander opsigte minder gesag het. Daarom vind hy dit 'n hermeneutiese uitvlug van die Ortodoksie toe hulle die Geloofsbelydenisse gaan sien het as die eintlike norm waarvolgens die Skrif dan geïnterpreteer moet word. So word dan ook die belydenis verswak in sy karakter as interpretasie van die Skrifinhoud, en gesien as subjektiewe maatstaf vir die waarheid, waaraan die Skrif eintlik moet beantwoord, deur dicta probantia vir alles te vind. Die Skrif het ook nie 
„perspicuitas" as eienskap nie, maar word duidelik alleen vir die geloof. ${ }^{7}$ )

\section{Wat beteken Sola Scriptura?}

Daar word dikwels op gewys dat Luther en die ander Hervormers die uitdrukking "sola Scriptura" nie in 'n dor skolastiese sin gebruik het nie. Vir Luther was Christus die lewende Woord van God, van Wie die Skrifte spreek en wat dan in die prediking verklank moet word. „Novi Testamenti ministerium non in lapideis et mortuis tabulis est deformatum, sed in vivae vocis sonum positum". Die Woord is evangelie wat kragdadig werk in die bediening van Woord en Sakramente. In dié sin kon Luther selfs verklaar dat „Ecclesia creatura est verbi". Die kerk is die skepsel van die Woord en moet dan ook steeds in diens van die Woord staan. ${ }^{8}$ ) Hieruit konkludeer Skydsgaard bv. in Barthiaanse trant dat as enige artikel van ons geloof (selfs die leer van die regverdiging uit die geloof alleen) of die woorde van die Bybel direk met Gods Woord geïdentifiseer word, daar 'n eienaardige verwarring ontstaan, waardeur 'n leerstuk of 'n boek (ook die Bybel, S.J.v.d.W.) verhef word tot die Woord van God. ${ }^{9}$ )

Hieroor nou 'n paar opmerkinge. Ons is wel bewus dat Luther wel in die begin enige moeilikheid gehad het met enkele Bybelboeke, soos bv. die Brief van Jakobus, waarvan hy nie goed geweet het hoe hulle inpas in die Kanon van die Bybel nie, maar wat hy tog later beter verstaan en hulle nooit verwerp het nie. Maar by ons wete het Luther nimmer daaraan gedink om binne die Skrifkanon te onderskei tussen die Skrifwoord en Gods Woord nie. Al was Christus vir hom die lewende Woord, het hy geglo dat Christus deur die Skrifwoord tot ons spreek en het hy hom daarom sterk verset teen die buitensporighede van die Geesdrywers. Met die Skrif in sy hand het hy al sy vyande tegemoet gegaan - die Bybel was vir hom die hoogste en laaste hof van appèl. Ons kan sê: Vir die Hervormers was dit, anders as by Rome: „Biblia Locuta, causa finita est". Dít sê ons vir Barthiane en almal wat op een of ander wyse allerlei foute of onbetroubaarheid by die Skrif meen te vind.

As Skydsgaard bv. sê: „For this living Word of God, which precedes and is over all things, is brought to the awareness of 
the Church precisely through the testimony of the Bible", dan beteken dit tog dat ons Christus uit cile Skrif leer ken. Maar as daardie getuienis nou bestaan in menslik-feilbare woorde en gedagtes, watter seke. ineid het ons dan dat die Skrif ons wel 'n suiwere beeld van Cirrisius gee en met watter maatstaf moet ons dan gaan bepaal wat eg en waar is en wat nie? Bly ons nie in die lug hang as ons, soos Skydsgaard, van die Bybel praat as 'n ,inciependent and sovereign voice", wat met ,sufficient lucicity and with authority" wys na die lewende Woord, maal dan weer in dieselfde asem sê dat die duidelikheid van die Evbel nie so is dat ons die inhoud in 'n "sisteem" kan uitciruk waarin al die frases en woorde in hul samehang en betekenis kan opgeneem word nie? ${ }^{10}$ )

Hoe kan Skydsgaard praat van die absolute prioriteit van die Bybel bokant clie kerk en dan sê: ,its represents in the Church the Word of God which is superior and antecedent to the Church and its faith"?'1) Dan het Christus maar 'n uiters swak en onvertroubare „representant” in die kerk, as dit Christus eerder verberg as openbaar. Hoe kan Skydsgaard vir Luther goedkeurend aanhaal waar Luther sê: „Tolle Christum e scriptura, quid amplius in illis invenies"? (Neem Christus uit die Skrif en wat vind jy verder daarin?,12) terwyl hy dan tog meen dat Christus nie oral te vind is nie, of liewer eintlik nêrens te vind is nie, altans nie so dat ons Hom in daardie woorde en frases kan vind nie? Word Christus dan nie vir ons juis lewend in die dooie letters of woorde nie, en is die Bartiane nic juis daaraan skuldig dat hulle Christus uit die Skrif wegneem nie?

3. Hoe ver strek die betckenis van die sg. "menslike faktor" in die Heilige Skrif?

Prof. H. Ridderbos het 'n serie artikels geskryf in die "Gereformeerd Weekblad", waarin hy sterk klem lê op die "menslikheid en relativiteit" van die Bybel, vir sover dit gesien word as 'n produk van menslike aktiwiteit. Hy erken dat hy te weinig dogmaties-histories geskoold is om te skrywe oor wat ons gewoond is om te noem die eienskappe van die Skrif In die sesde artikel bespreek hy die duidelikheid (perspicuitas) van die Skrif. ${ }^{13}$ ) Hier blyk dit hoe verstrik 'n mens raak as jy, soos Ridderbos, gelowig wil vashou aan die onfeilbare gesag 
van die Skrif as Gods Woord en terselfdertyd die menslike faktor i.v.m. die Bybelskrywers so ver wil deurvoer dat hulle nie alleen in hul eie taal en styl geskryf het nie, maar ook in terme van hul wêreldbeeld en natuurkennis (of - onkunde?)

Die ecrste waarop ons wil wys is dat Ridderbos verklaar dat ,het Woord Godls zozeer in het menselijke is ingegaan en het zich daarmee zozeer heeft één gemaakt, dat wij, ook vanwege deze menselijkheid van de Schrift, altijd weer voor de vraag zullen staan wat het onaantastbaar goddelijke en wat die relativiteit van het menselijke in de Schrift in concreto betekent". Hier is Ridderbos op tiiters gevaarlike grond. Sekere dinge sou dan in die Skrif wel ",aantastbaar" wees, solank die goddelike maar net nie aangetas word nie. Ons het hier ' $n$ ander vorm van dualistiese inspirasie-leer, en niemand sal kan bepaal wat Goddelik-onfeilbaar is en wat menslikfeilbaar is nie. Te meer nog daar Ridderbos tot hierdie menslikbetreklike ook reken voorstellinge en voorveronderstellinge „die wij ons nict meer kunnen toeëigenen of indenken" en wat wel tot die opvattinge van die Bybelskrywers, maar nie meer tot ons opvattinge behoort nie. Dit het skynbaar nie tot Ridderbos deurgedring dat God die Heilige Gees, as die Outeur van die Skrif, die Bybelskrywers so geïnspireer het dat hulle nie maar enige tyd-historiese elementc in die Skrif opgeneem het nie, maar alleen dit wat waaragtig en betroubaar is en wat ewig waar en blywend is. Ridderbos sien die Bybel te veel as 'n menslike poging om die Goddclike dinge weer te gee en te min as 'n Goddelike openbaringswerk in terme van menslike taal en uitdrukkingswyse.

Ridderbos erken dat ons nie net in die sg. Soteriologiese gedeeltes van die Skrif nie, maar ook in die Historiese gedeeltes te doen het met ",héél de Schrift", wat dus nie van mekaar te skei is nie. Hy sê die Skrif wil ons nie net inlig oor die mens se verhouding tot God nie, maar ook oor "het vanwaar en waartoe en waarheen van heel de wereld". Die Skrif wil ons dus ook gee "kennis van de historie".

Ridderbos se artikel skep wel die indruk van iemand wat nie seker is van homself nie. Hy wil vashou daaraan dat die hele Bybel, ook die historiese gedeeltes, 'n openbaringskarakter het as Woord van God. Tog wil hy opening laat vir menslikfeilbare dinge wat in die periferie van die Skrif wel 'n plek sou hê. So breck hy die dyk van Goddelike onfeilbaarheid van die 
Skrif en moet dit lei tot ' $n$ katastrofale verspoeling van alle sekerheid en vastigheid t.o.v. die gesag van die Skrif.

\section{Interpretasie en subjektiwisme.}

Daar word besonder klem gelê in ons tyd op die feit dat waarheid altyd geïnterpreteerde waarheid is. Die hermeneuse word dus die spil waarom alle menslik kenne draai en wat vir die een waar is, hoef dus nie noodwendig vir die ander ook waar te wees nie. Waarheid is altyd waarheid soos ons dit verstaan. Ons dra alleen kennis van die fenomenale dinge en nie van die „Ding an sich" nie. Daarom moet ons versigtig wees om nie ons sieninge te verabsoluteer nie.

In 'n artikel in „De Reformatie" bespreek dr. C. Trimp hierdie probleem i.v.m. 'n brosjure van H. J. Nieboer: „Verantwoording en analyse". ${ }^{14}$ ) Nieboer het dit veral oor die moontlikheid dat die Belydenis verskillend geïnterpreteer kan word. 'n Inhoud wat nie geïnterpreteer word nie, sê hy, het geen inhoud nie. Hiervan sê Trimp dat as ons so 'n beginsel streng sou deurtrek, dan beteken dit dat nie die Bybel of die Belydenis of enige ander geskrif sy eintlike inhoud aan ons sou kan bekendmaak nie. Alles moet eers uitgelê of geïnterpreteer word en sou die interpretasie ook weer 'n interpretasie nodig hê. Weliswaar is die moontlikheid van misverstand of wanbegrip natuurlik altyd daar. Maar dit beteken nog nie dat daar geen voertaal kan wees wat dit moontlik maak dat God met ons of ons met mekaar kan spreek en tot mekaar kan deurdring nie. Trimp wys in hierdie verband op die werking van die Heilige Gees, waardeur God se Woord, wat in homself deursigtig is, oormag oor ons verkry en ons also kom tot 'n klare belydenis van wat God aan ons geopenbaar het.

Ons mag dus nie die werking van die Heilige Gees gaan versubjektiveer nie. Trimp wys daarop dat die Gees die kerk lei in alle waarheid en ons also bewaar om te versink in het oeverloos moeras van de interpretatie". Daarom kan ons belydenis doen van ons ,algemeen en ongetwijfeld christelijk geloof". Dit beteken nog nie verabsolutering van ons Belydenis nie, of dat die Belydenis nie steeds onderworpe is en bly aan verdere en diepere bestudering van die Skrif en besinning oor die inhoud daarvan nie. Maar wel beteken dit dat die Waarheid objektief vasstaan voordat ons dit kan probeer 
interpreteer, en dat daar inderdaad die moontlikheid is om onder die verligting van die Heilige Gees die regte interpretasie te bekom en te bely. Trimp wys op sulke tekste soos 1 Kor 2:16; 2 Petr. 1 : 19; 1 Joh. 2 : 21; 2 Joh. 1 : 2; 2 Joh. 9; Ef. $3: 18$. Hy verwys ook na Calvyn wat gesê het dat die Skrif die skool is van die Heilige Gees, waar ons alles kan en moet leer wat God wil hê dat ons moet weet, Inst. III, 21, 3.

Dit alles kom o.i. neer op die vraag of dit moontlik is dat daar 'n persoonlike kontak tussen God en ons en tussen mense onderling kan wees? Is dit moontlik dat Christus, die Woord van God, wat uitgedruk is in Natuur en Skriftuur tot ons kan deurdring en in ons kreatuurlike gestalte kan aanneem? Is dit moontlik dat ons buite onsself kan tree en gemeenskap met andere kan beoefen, of is ons soos deur ' $n$ kopermuur in ons eie subjek vasgekerker, vir ewig eensaam en afgesonder?

\section{Hermeneuse verdring die Heilige Gees.}

Alle interpretasie van die Heilige Skrif gaan uit van een of ander standpunt. Die Bultmanskool noem dit 'n „Vorverständnis". Vir hulle moet een en dieselfde maatstaf vir historieskritiese ondersoek van die Skrif toegepas word as vir enige ander literatuur. Daar mag nie vir die Skrif 'n "dogmatiese" uitsondering gemaak word nie. Vir Bultmann en sy skool kan daar net één regte begrip (interpretasie of „vertaling") van die Skrif wees en dit is die eksistensialistiese, nl. wat die Skrif ons wil sê t.o.v. die egte, outentieke eksistensie, wat ons (elkeen vir homself) hier en nou moet nastrewe. Dit is die een en al van die Skrifboodskap.

Carl E. Braaten wys daarop dat daar op dié wyse 'n reduksie plaasvind en dat die Skrif veel meer te sê het as net hoe ons outentiek moet bestaan, nl. uitsprake oor God, die wêreld, die geskiedenis, die kerk, ens. Maar vir Bultmann en sy skool is al hierdie dinge eintlik maar theolegoumena in mitiese vorm. Die geloof word nog wel objektief aan die „Kerugmatiese" Christus verbind, maar is geensins iets objektiveerbaars nie. Braaten praat van die „horror of so-called 'objectifying' thinking and speaking" van die moderne teologie, en hy sê dat ons sonder objektiverende begrippe eenvoudig geen kennis kan hê nie en net sal moet swyg. ${ }^{15}$ ) Volgens Braaten sal die Teologie dus moet besluit of dit as 'n weten 
skap wil uitgaan van sekere dogmatiese voorveronderstellinge en of dit 'n algemeen-filosofiese onderbou moet hê wat hom ten slotte sal vernietig. Hy vra hoe lank die Teologie op so 'n "starvation diet" soos die van die eksistensie-teologie sal kan voortbestaan. ${ }^{16}$ )

Braaten wys verder daarop dat die Evangelie by die Bultmann-skool (veral by manne soos Ebeling en Fuchs) feitlik opgelos word in 'n Woord-gebeure, waarby Jesus nie meer as persoon van belang is nie, maar ' $n$,language event", waarby ons dan alleen vra na watter "taal" die Jesusfiguur spreek tot die moderne mens. Kruisdood en opstanding is nie meer die kerugmatiese sentrum nie, altans nie as historiese gebeurtenisse nie. Alleen die idee of boodskap vir 'n outentieke eksistensie wat daaruit tot ons spreek, is van belang. So is dan ook die hele O.T. van weinig belang, en alles draai net om die Nieu-Testamentiese Christusboodskap. Braaten beskuldig Bultmann hier van Marcionitisme. Hy sê dat die filosofie van Heidegger by Bultmann die plek inneem van die O.T., en dat die krities-historiese metode, ,the hall-mark of liberal theology", die plek inneem van die kerklike Belydenis. Teenoor Bultmann, sê hy, het Barth getrag om in sy teologie sowel die historiese as die teologiese benadering vas te hou, alhoewel hy volle reg gegee het aan die historiese kritiek, maar ten diepste tog sy dogmatiek opgebou het op die inspirasie-gedagte, al was dit dan ook sy eie inspirasiebeskouing. ${ }^{17}$ )

Hier kan ons net sê dat o.i. Barth, juis omdat hy die histories-kritiese metode ook ruimte wou gee, om dan ,wetenskaplik" voor te kom, in prinsipe die Godsopenbaring prysgegee het en dat Bultmann meer konsekwent as Barth is in sy toespitsing op 'n Woord-teologie of kerugmatiese (histories ontledigde) Christus-idee. Braaten wys tereg daarop dat vir die histories-kritiese benadering die Bybel as Kanon geen betekenis het nie en dat die hele metode geen rekening hou met die kerk as integrale deel van die „ongoing salvation-history" nie. Dis die Gees, sê hy, wat die kerk lei in alle waarheid. Dieselfde Gees wat in die Skrif spreek, spreek ook in ons harte. Anders is die teks van die Skrif 'n dooie letter. ${ }^{18}$ )

In hierdie verband kan ons ook let op wat Kuitert skryf oor dieselfde saak. Hy uys op die onproporsionele aksent wat tans op die hermeneutiek gelê word as filtreerfunksie, om deur die hermeneutiese metode op te los „waarvoor de dogmatiek 
zich vroeger op de Heilige Geest beroep". In plaas van die Gees het die teks nou ,laatste subject" geword.19) Kuiters sê dat Bultmann, sowel as Fuchs-Ebeling, die ou dogmatiese standpunt afwys as Supranaturalisme. Hulle wil die Skrif interpre. teer uit die menslike, „existenz"-gedagte. Hermeneutiek is "Daseinsanalyse, anthropologie, uitleg van het ware mens-zijn". Funksioneel gesien neem die Hermeneutiek hier die plek in van die Apologetiek: „het acceptabelmaken van het Christelijk gelool". Kuitert wys dan daarop dat die Skritboodskap juis vir die sondaal "onacceplabel" is; 1 Kor. 2 : 14. Dis die Gees wat oortuig van sonde, geregtigheid en oordeel: Joh. $16: 8-11$. Die historiese Jesus van die Skrifte moet eers tot Christus word deurdat Hy deur die filter gaan van wat die moderne mens meen „wat-kan-en-wat-niet-kan". So word die heilsboodskap van die Skrif dan verskraal. ${ }^{20}$ ) Kuitert sê dat by manne soos Van Buren en Robinson God die Vader ("God out there") vervang is deur die afgod van „medemenslikheid". In die prediking kry ons dus maar eintlik net 'n bespiegeling oor die egte mensu'ees, stigtelikheid, moralisme.21) Die Godsopenbaring word ten slotte gelyk geskakel met ons subjektiwistiese siening oor die mens.

Ons kan Kuitert dit alles toestem. Maar as hy dan meen dat Barth hier redding bied, dat ons vrye spel moet gee aan die "research work" van die historikus en clat die mens (d.w.s. die gelowige) so met die Goddelike „partner” gekorreleer moet word dat hy as verifikasie-instansie kan dien, dan vrees ons dat Kuiters (in sy vrces vir fundamentalisme) onder bekoring van die moderne wetenskapsideaal weer 'n ander soort "filter" gaan gebruik om die volle openbaring van die Skrif te reduseer.

As ons die Skrif gaan onderwerp aan die kritiek van ons menslike insigte, dan het ons prinsipieel die objektiwiteit van die openbaring prysgegee en word ons noodwendig teruggeroep in subjektiwileit en word die mens (anthropos) die maatstaf van die ewige waarheid, hoe idealisties en historisties ons die mens dan ook al gaan verbind met die vleesgeworde Woord, d.i. Jesus Christus. Daarom is Barth se denke in wese eksistensialisties, al wil hy nie uit die Eksistensie-filosofie sy teologie opbou nie. Die verskil tussen hom en Bultmann is dat hy trag om die menslike eksistensie uit Christus volgens die (menslikfeilbare) getuienis van die Skrif op te bou, terwyl Bultmann dit eerder uit die algemene menssyn a la Heidegger opbou. 
In die sin is Barth se teologie seker meer "Christelik" as dié van Bultmann.

Ewewel, die Christus van die Skrifte is vir ons in beide gevalle weg. Ons het geen objektiewe norm meer nie. Ons weet net van Hom omdat en in sover Hy nou en hier direk Homself aan ons openbaar, al is dit dan ook in aansluiting by die Skrifgetuienis. Nie die Skrif nie, maar die Christus in ons is die laaste en hoogste norm van Godsopenbaring en Godskennis.

Ons het hier dus te doen met 'n humanistiese interpretasie van Gods Woord, wat in teëstelling met die ou-modernisme die mens nie staties-ontologies besliou nie, maar in nu-modernistiese trant dinamies-funksioneel. Maar dit bly in wese antropologies-humanistiese ontleding van die mens, wat by Barth sy epi-sentrum vind in dié Mens, Jesus Christus, uit Wie en deur Wie en tot Wie alle dinge is.

\section{Die kwessie van literêre genre.}

In 'n artikel in "Gereformeerd theologiesche tijdschrift", Jrg. 65, No. 2, oor „Het soortelijk gewicht van de historische stoffen van het O.T." maak Koole sekere opmerkinge waaraan ons hier ons aandag moet gee. Hy verklaar baie stellig dat die kerugma van die historiese oorleweringe ontkrag word as ons die faktisiteit daarvan wegneem. ${ }^{22}$ ) Die kerugma staan en val dus met die historiese gebeurtenisse waarvan dit spreek.

Maar dan verklaar Koole in dieselfde asem dat die geskiedskrywers nie deur "inspiratie" die gebeurtenisse opgeteken het (soms lank nadat dit plaasgevind het) nie. „Noch in het N.T., noch in het O.T. beroept zich ook maar één bijbels geschiedschrijver op Goddelijke ingeving ais bron van kennis". Hulle het, sê Koole, hul feitemateriaal langs gewoon menslike weg verkry. ${ }^{23}$ ) Koole onderskei hier dus nie goed tussen revelasie en inspirasie nie. Dis tog onloënbaar dat God dikwels op baie tye en maniere in die ou tyd tot die vaders gespreek het deur die profete: Hebr. 1: 1. Die inspirasie het hulle gedring om te spreek of te skryf en hulle daarby gelei in die onfeilbare hantering en optekening van die stof, al het hulle ook baie van die materie uit die oorlewering of uit dokumente verkry.

Koole wil dan heelwat konsekwensies daaruit trek dat baie van die historiese stowwe in die vorm van sg. volksverhale oor- 
gelewer is. So vind hy sekere „anakronismes" in die O.T., verhale, bv. wanneer gesê word dat die aartsvaders kamele gehad het in plaas van esels. Ook meen hy uit Ex. $6: 2$ te kan aflei dat Abraham nie werklik die Here geken het onder die naam Jahwe nie, al sê die Bybel ook anders. ${ }^{24}$ ) Hy verwys ook na die drywende byl (Elisa) en na die wondersiklusse, bv. die uittog van Israel uit Egipte en die verowering van Kanaän wat eintlik ten doel het om die mag en goedheid van God te beklemtoon in sy heilige oorlog teen die Bose. In die N.T. wil die opstanding en wonders wys na die baanbrekende koms van die koninkryk. ${ }^{25}$ ) Koole wil dan nie die feitlikheid van die wondere ontken nie, maar juis handhaaf. Maar waarom hy dan so benadruk dat ons hier te doen het met „populaire volksverhalen" is nie duidelik nie. Uit sy betoog wil mens tog die indruk kry asof hy van gedagte is dat ons met die wonders eintlik te doen het met "natuurlike dinge, wat dan in 'n bonatuurlike lig gestel word deur die Bybelskrywers". As dit die geval mag wees, sou ons ten sterkste beswaar moet maak teen so 'n opvatting.

Wat hy opmerk i.v.m. die getalle wat in die O.T. voorkom, bv. die ouderdomme van Abraham, Isak en Jakob, wat hy meen dat dit miskien in verband staan met die stylvorm van die literêre genre van oud-Oosterse oorlogsliteratuur, mag daar miskien iets in steek as ons meer gegewens daaromtrent kan kry. Maar op die oomblik lyk dit ook nog maar baie twyfelagtig en sou ons seker op spekulasie bou as ons dit as 'n kunsmatige konstruksie wil sien, soos Koole doen. ${ }^{26}$ )

O.i. word in die hele betoog oor literêre genres te veel nadruk gelê op die menslike faktor, terwyl die Goddelike faktor haas uitgeskakel word. Wat van die pneumatiese literêre genre (inspirasie deur die Heilige Gees) wat alle menslike genres opneem en louter? Word daar wel genoegsaam rekening gehou met die feit dat dit die Heilige Gees is wat die eintlike Outeur van die Ou en Nuwe Testament is? As ons daar nie op let nie, beweeg ons inderdaad op baie dun ys. Die Bybelse geskiedenis is God se getuienis; vgl. 1 Joh. 5 : 9-11.

\section{Ontmoetingsdenke.}

Dr. H. Berkhoff maak in sy rede: „God voorwerp van wetenschap?" 'n hele paar baie behartigingswaardige opmerkin- 
ge. $\left.{ }^{27}\right)$ Hy sê bv.: „In elk geval is er in en buiten de theologie een denktrant ontstaan, die we ,ontmoetingsdenken' kunnen noemen". ${ }^{28}$ ) Hy verwys na Martin Buber se "Ich und Du", volgens wie God vir ons alleen in die "Gegewart" in direkte ontmoeting kenbaar is. So gou ons oor God besin, word $\mathrm{Hy}$ objek en dan verander die Ich-Du-verhouding in lch-Es-verhouding en dan het ons nie meer met God te doen nie.

Berkholf sê dat dieselfde idec ook in die eerste fase van die Dialektiese Teologie gevind word. Hy wys dan veral op Bultmann en Brunner, alhoewel dit geensins duidelik is waarom hy Barth hier uitsonder nie. Berkhoff sê dat hierdie denkvorm gebore is uit reaksie teen die ek-eensaamheid van die idealistiese denke, maar ook teen die positivisme en versaakliking van die lewe. Tog het Kant, Kierkegaard, Ritschell e.a. ook hierdie nuwe denkwyse voorberei. In hierdie denke vind ons dan 'n voorliefde vir die dinamiese bo die statiese, vir die relasie bo die substansie, vir akte bokant synde. Dit aksentueer die kommunikasie en die dialoog. Die Waarheid is nie Iets nie, maar Iemand; God is eintlik Ereignis of 'n gebeure en word alleen só geken en nie as objek nie. ${ }^{29}$ ) Dit verset hom teen die sg. toeskouers-denke, wat met die Griekse denkwyse vereenselwig word, in teëstelling met die Israelitiese relasionele denkwyse.

Berkhoff wys dan claarop dat hierdie ontmoetingsdenke, streng deurgevoer, leeg bly en eintlik alle teologie ophef en die tak afsaag waarop die denke self sit. ${ }^{30}$ ) By die Bultmann-skool is die Dogmatiek vervang deur die Hermeneutiek. Dit gaan dan om die ,boodskap" wat in en deur die teks tot ons spreek en wat ons eksistensialisties moet ,interpreteer". Die ontmoeting word losgemaak van elke historiese aspek en word daarmee „tydloos, spookachtig, bloedloos en schraal, een wereld van pure innerlijkheid" ${ }^{31}$ ) Al wat oorbly is 'n vae, inhoudlose boodskap van ,vergewing" of rekonsiliasie met ons eie bestaan. Die Heilsgeskiedenis het niks met ons profane „Historie" te doen nie. Jesus as mens is nie identiek met die Christus nie. Sy opstanding is nie in historiese kategorieë uit te druk nie. „Het resultaat van dit alles is een scheiding van Woord en werkelijkheid, die het Woord abstraheert en die werkelijkheid profaneert".

Berkhoff beklemtoon dus die historisiteit van die openbaring en sê dat God meer is as net 'n pool in 'n relasie, maar 
Een wat in ons menslike lewe en wêreld indring en daar byna in 'ondergaan en dit omskep tot 'n nuwe werklikheid. In die middelpunt van dit alles is die vleesgeworde Woord, waarin God Homself tot objek gemaak het. Die heil in Christus „gaat in in de objektiveerbaarheid en neemt de gestalte aan van een boek, een leer, een instituut..." (Onderstreping deur ons, S.J. v.d.W.). Berkholf sê dat die geloof bestaan uit kennis en vertroue (Heid. Kal., vr. 21). „Het gaat om de éne Waarheid, maar zij bestaat in een veelheid van waarheden". Hy waarsku om nie 'n oordrewe teenstelling tussen Griekse en Hebreeuse denke te maak nie. Die één sluit die ander nie volkome uit nie. Om oor God te dink (teologiseer) geskied alleen in aanbiddende toenadering tot Hom en ons kan geen verhouding tot God verkry as ons nie iets weet van Wie $\mathrm{Hy}$ is nie. Geloof en wete staan nie los naas mekaar nie, maar deurdring mekaar. ${ }^{32}$ )

Ons is dankbaar vir hierdie suiwere klanke wat Berkhoff laat hoor. Die tragiese bly egter nog steeds dat die "boek" wat Berkhoff van praat, nl. die Skrif, ook vir hom nie aanvaarbaar is as die historiese vertroubare en onfeilbare Woord van God nie. Ook hy saag aan die tak waarop hy sit, soos Barth.

P.U. vir C.H.O.

S. J. van der Walt.

1) Vgl. p. 285 e.v.

2) Id. p. 288.

3) Id. p. 304

4) Id. p. 305 .

5) Id. p. 318 e.v.

6) Id. p. 320 e.v.

7) Id. p. 331 e.v.

8) Vgl. K. E. Skydsgaard in "Studia Theologica”, vol. 19, no. 1-2, p. $221-224$.

9) Id. p. 224

10) Id. p. 225

11) Id. p. 227.

12) Id. p. 226 (daarin, in illis, sien op dic woorde in die Skrif).

13) Kyk Jrg. 20, No. 41

14) De Reformatie, Jrg. 40, No. 39, p. 313.

15) C. E. Braaten: „How new is the new hermeneutio?” in "Theology today". Vol. XXII, No. 2, p. 223.

16) Id. p. 226.

17) Id. p. 232.

18) Id. p. 233. 
19) H. M. Kuitert: „Verschraling of verrijking”. Art. in „Kerk en Theo logie". Jrg. 16, No. 3; p. 201.

20) Id. p. 202.

21) Id. p. 204.

22) Vgl. "Geref. Theol. Tijdschrift". Jrg. 65, No. 2, p. 83.

23) Id. p. 84.

24) Id. p. 92.

25) Id. p. 93,94

26) Id. p. 98.

27) Uitg. G. F. Callenbach, Nijkerk. Uitgespretk op 7 Okt. 1960

28) Id. p. 7

29) Id. p. 7

30) Id. p. 8,9

31) Id. p. 8

32) Id. p. $12-17$ 